\title{
Estudio de las decoraciones murales ocultas del Teatro Italia, en Gualeguay (Entre Ríos, Argentina) ${ }^{[1]}$
}

\author{
María Alejandra Gómez Paredes, Daniel Alberto Saulino
}

Resumen: El objetivo de este trabajo es estudiar las decoraciones murales de la sala del Teatro Italia. Partiendo de diversas hipótesis que formulan la existencia de antiguos diseños bajo los sencillos y despojados recubrimientos modernos que hoy se pueden observar y aplicando diversas metodologías de procesamiento y análisis de imágenes, pudimos confirmar dichos indicios. Los resultados nos permitieron desarrollar una reconstrucción digital virtual de alguno de los posibles momentos históricos-estéticos. Mediante esta técnica pudimos interpretar el aspecto de este bien cultural, de manera virtual y anticipada, en vista de una eventual propuesta de restauración. Cabe señalar que estos estudios forman parte de un proyecto mayor, todavía en curso, que investiga cinco teatros líricos argentinos y sus contextos, articulados en torno al eje fluvial del río Paraná. Ese proyecto, abordado desde diversas dimensiones materiales y simbólicas, pretende reunir un conjunto de instrumentos analíticos para la preservación, conservación y restauración de los mismos.

Palabras clave: estarcido con plantillas, imagen subyacente, teatro italiano, reconstrucción virtual

\section{Study of the hidden wall decorations of the Teatro Italia, in Gualeguay (Entre Ríos, Argentina) ${ }^{[1]}$}

Abstract: The aim of this work is to study the wall decorations of the room of Teatro Italia. Starting from various hypotheses that formulate the existence of ancient designs under the simple and stripped-down modern coatings, we were able to verify their existence by applying various image processing and analysis methodologies. The results allowed us to develop a virtual digital reconstruction of some of the possible historical-aesthetic moments. By means of this technique we were able to interpret in a virtual and anticipated way, the previous aspect of the room in view of a possible restoration proposal. It should be noted that these studies are part of an ongoing project that investigates five Argentine lyric theaters and their contexts, all of them located on the Paraná river area. The project aims to bring together a set of analytical instruments for the preservation, conservation and restoration of those theaters.

Keyword: stencil, underlying image, Italian theater, virtual reconstruction

\section{Estudo das decorações ocultas das paredes do Teatro Italia, em Gualeguay (Entre Ríos, Argentina) ${ }^{[1]}$}

Resumo: O objetivo deste trabalho é estudar a decoração das paredes da sala do Teatro Itália. Partindo de várias hipóteses que formulam a existência de desenhos antigos sob os revestimentos modernos, simples e despojados que podem ser observados hoje, e aplicando várias metodologias de processamento e análise de imagens, podemos confirmar essas indicações. Os resultados permitiram desenvolver uma reconstrução digital virtual de alguns dos possíveis momentos histórico-estéticos. Através desta técnica podemos interpretar o aspeto deste bem cultural, de forma virtual e antecipada, tendo em vista uma eventual proposta de conservação e restauro. Cabe destacar que esses estudos fazem parte de um projeto maior, ainda em curso, que investiga cinco teatros líricos argentinos e os seus contextos, articulados em torno do eixo fluvial do rio Paraná. Este projeto, abordado a partir de várias dimensões materiais e simbólicas, visa reunir um conjunto de instrumentos analíticos para a sua preservação, conservação e restauro.

Palavras-chave: estampilha, imagem subjacente, teatro italiano, reconstrução virtual 


\section{Introducción}

Entre los edificios característicos de las pequeñas ciudades que crecieron con la transformación de la Argentina en las últimas décadas del siglo XIX y las primeras del XX, están los teatros. A su modo representaban la voluntad y la vocación de modernización/europeización tal cual la imaginaban los grupos dirigentes locales y regionales. Algunos de esos teatrosfueron creados exnihiloy otros fueron readaptaciones de antiguos salones dedicados a las actividades de una asociación local. El último es el caso que aquí tomaremos en consideración: el teatro Italia de la sociedad del mismo nombre en la ciudad de Gualeguay, en la Provincia de Entre Ríos. El hecho de que el teatro local existente se incendiase poco antes de las celebraciones del considerado primer centenario de la Argentina (1910) llevó a la readecuación de la sala de una Sociedad de Socorros Mutuos, como lugar principal para presentaciones musicales. El teatro presenta entonces, un interesante desafío para el estudio de los aspectos formales y materiales de los recubrimientos pictóricos y decorativos que contienen la historia del teatro y sus transformaciones desde los orígenes hasta el presente. El momento actual nos habla así del pasado, pero para descifrarlo es necesario recorrer el camino inverso e ir develando las sucesivas capas materiales, pero también de algún modo simbólicas, que lo recubren.

Nuestro objetivo es estudiar parte de las decoraciones murales, partiendo de la constatación de la existencia de antiguos diseños ornamentales subyacentes y ocultos bajo los sencillos y despojados recubrimientos modernos que hoy se ofrecen a la mirada de los visitantes. Nos aproximaremos a una caracterización material y, en base a los resultados obtenidos en el curso de la investigación, propondremos un posible modelo de reconstrucción virtual. Asimismo, cumpliendo con uno de los objetivos del proyecto: relevar, identificar y relacionar los aspectos materiales de las salas teatrales en estudio, procuraremos distinguir los recubrimientos pictóricos y decorativos, que podrían ser considerados con un buen grado de probabilidad, como los originales.

Desde nuestro primer encuentro con la sala del teatro Italia, pudimos percibir evidencias de algunos rastros de relieves en la pared, que por su recorrido hacían presumir la existencia de motivos decorados subyacentes a la capa de pintura blanca actual. Ese relevamiento preliminar orientó la invesigación hacia diferentes hipótesis:

- una decoración pintada sobre la pared

- un empapelado con un ligero relieve

- un revestimiento de tela adherido sobre el muro (la menos probable).

Durante el proceso de localización e identificación, pretendimos apreciar su calidad material, estudiar las formas, el color y la textura de los diseños.

A partir de la documentación gráfica y estratigráfica obtenida, nos propusimos componer un mapa virtual que posibilitase la visualización e interpretación del contexto ambiental del interior de la Sala Teatro, donde esas decoraciones tuvieran su protagonismo. Estos modelos virtuales, basados en la investigación y documentación recopilada en el archivo de la institución, creemos serán de gran utilidad en el momento de discutir las posibles opciones que permitan planificar futuras actividades de Conservación Restauración del predio.

\section{Orígenes del Teatro}

La sala del Teatro Italia fue creada como el salón teatral y de festividades de la Sociedad Italia de Socorros Mutuos y Beneficencia, institución que funcionaba desde 1868 en la ciudad entrerriana de Gualeguay. Esta asociación edificó primero, hacia 1872, el predio que marcó el comienzo de las actividades societarias de asistencialismo. Con posterioridad, anexó el terreno donde se levantaría el edificio teatral (Devoto 2006) ${ }^{[2]}$, destinado a albergar acontecimientos artísticos, sociales y patrióticos de la colectividad italiana. Como lo indica el mismo frontis del edificio teatral, en 1902 comenzaron las obras de su construcción, hechas posible por la recolección de contribuciones de los asociados desde el año anterior. [Figura1 A].

Inaugurado oficialmente el 11 y 12 de marzo de 1903, la prensa local detalla los actos y las presentaciones musicales que acompañaron al estreno de la nueva sala que ostentaba la comunidad italiana de Gualeguay. Destacaron el "verdadero éxito y esplendor" (El Debate 10/10/1903) de los festejos, [Figura $1 \mathrm{~B}$ ] que se sucedieron por espacio de todo el día, con una vasta e inusitada concurrencia que ocupaba el "amplio y hermoso salón profusamente iluminado" (EI Debate 14/10/1903) de la flamante sala de encuentros.

"El salón-teatro era similar a los de otras sociedades italianas de socorros mutuos: un escenario elevado al fondo de un salón rectangular equipado con sillas, que podía albergar tanto representaciones teatrales como conferencias, asambleas o bailes". (Bernasconi 2017) [Figura1D]. Desde luego que todo ello era posible porque Gualeguay era por entonces una ciudad que, gracias a su conexión por medio del que fue el primer ferrocarril de la provincia, con un activo puerto fluvial sobre el río Paraná, vivía una prosperidad vinculada a su creciente actividad ganadera, a sus ricas colonias agrícolas y a la creación de nuevas industrias que elaboraban productos primarios. Notorios aspectos que hacían de la ciudad desde fines del siglo XIX, un importante centro económico y cultural, reflejado en la vitalidad del movimiento asociativo ya que sus habitantes habían constituido, además de la sociedad italiana, la sociedad española (1879), la francesa (1881), una argentina de socorros mutuos (1884) y una de fomento educacional (1892) (Bernasconi 2017).

La ciudad contaba ya con un teatro acorde a sus ambiciones; antes de la construcción de la sala teatral 


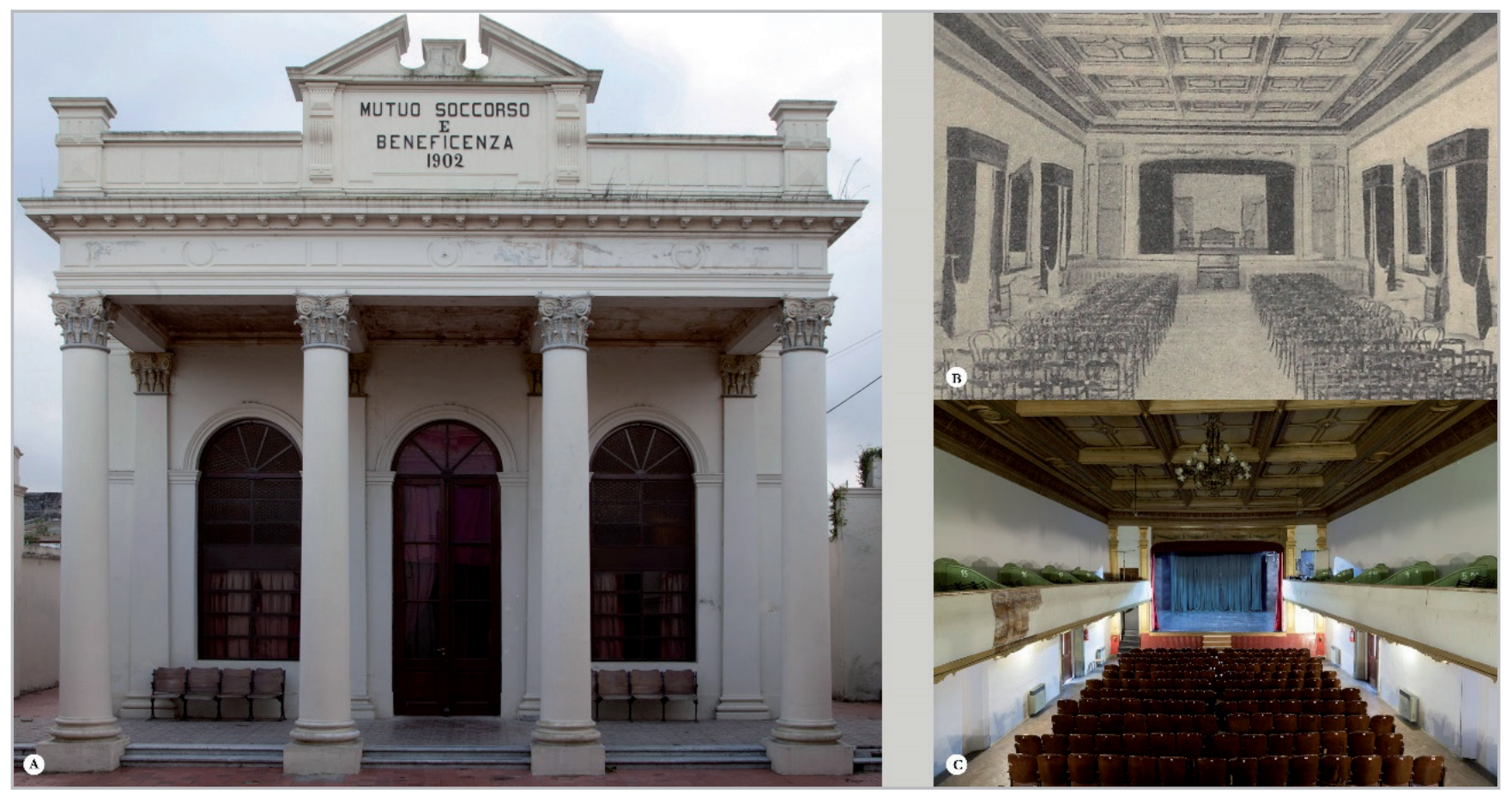

Figura 1.- Gualeguay A:Teatro Italia. Fachada, aspecto actual y patio interior de la Sociedad Italia. B: Salón teatral de la Sociedad Italia. Vista de la planta única del salón antes de la reforma de 1910. C: Teatro Italia. Interior de la sala, vista actual de las reformas con la inclusión de la línea de palcos.

de la Sociedad Italia, había visto la luz el teatro Nacional -nacido gracias al esfuerzo solidario y el aporte mediante la compra de acciones por un grupo de sus habitantes- con una capacidad de 700 plazas, e inaugurado el 28 de marzo de 1891 [Figura 1C)]. Intensa fue su actividad, entre óperas, zarzuelas, representaciones teatrales, reuniones sociales y funciones de cine en los años de su existencia. En marzo de 1910, en el transcurso de una proyección fílmica, se desató el incendio que lo hizo desaparecer por completo (Vico 1976).

Este sorpresivo acontecimiento modificó buena parte del destino y de la fisonomía de la sala de reuniones de la Sociedad Italia. A partir del siniestro, la sala tuvo la oportunidad de ocupar esa vacancia, transformándose desde ese momento en el Teatro oficial de la entera comunidad y no sólo de la italiana, lo que le añadió un protagonismo por buena parte del siglo XX. Esa tradición contribuyó a que, en el año 2015, fuera declarado, junto al resto del conjunto edilicio, Bien de Interés Histórico Nacional.

\section{Funciones, Transformaciones y Reformas}

El grueso de las reformas que reacondicionaron el funcionamiento para su nuevo e inesperado papel fueron iniciadas en 1910. Las adaptaciones se enfocaron en la necesidad de aumentar las localidades de espectadores y la solución consistió en construir una serie de palcos, dos de avanzada, inexistentes en la actualidad, y otros que abarcarían, todo el perímetro del salón en modo de emparentarlo a la tipología de los teatros existentes en tantas ciudades de las provincias argentinas [figura1 E]. Existía un particular interés de los responsables de la sociedad por moderar los costos involucrados en esas reformas, a fin de no comprometer otras actividades, pero también existía, muy probablemente, una sensibilidad y un afecto especial por el antiguo salón, lo que sugería realizar las reformas en el recinto ...rispettando l'estetica dell'attuale ambiente ${ }^{[3]}$. De esta manera, la readaptación y creación de los nuevos espacios y sus ornatos deberían imperiosamente estar en conjunción con los ya existentes.

Gracias a la documentación fotográfica existente del pasado del teatro ${ }^{[4]}$, que nos permitió hacer comparaciones con el estado actual, se pudo realizar una primera aproximación a los cambios estéticos que habían tenido lugar en el recinto. Una primera observación denota que la sala, entre su nacimiento y la reforma sucedida en 1910, presentaba una planta única exenta, con tres puertas frontales y seis laterales. Las paredes interiores aparecían cubiertas con un decorado de diseños repetitivos, enmarcado por guardas también decoradas. Este acabado se percibía ubicado por encima de lo que podría ser una moldura o panel colocado a una distancia aproximada de 1 metro del pavimento, y que seguía las normativas del tradicional diseño tripartito para la decoración del muro, impuesto por la usanza del momento [Figura 2A]. A ambos lados del escenario, y enmarcados por sendas pilastras, se hallaban motivos en apariencia pintados que se unían a los frontales superiores del arco de proscenio [Figura 2A]. De estos antiguos diseños, sólo se observan en la actualidad los dos últimos, correspondientes al panel central superior de la boca del 


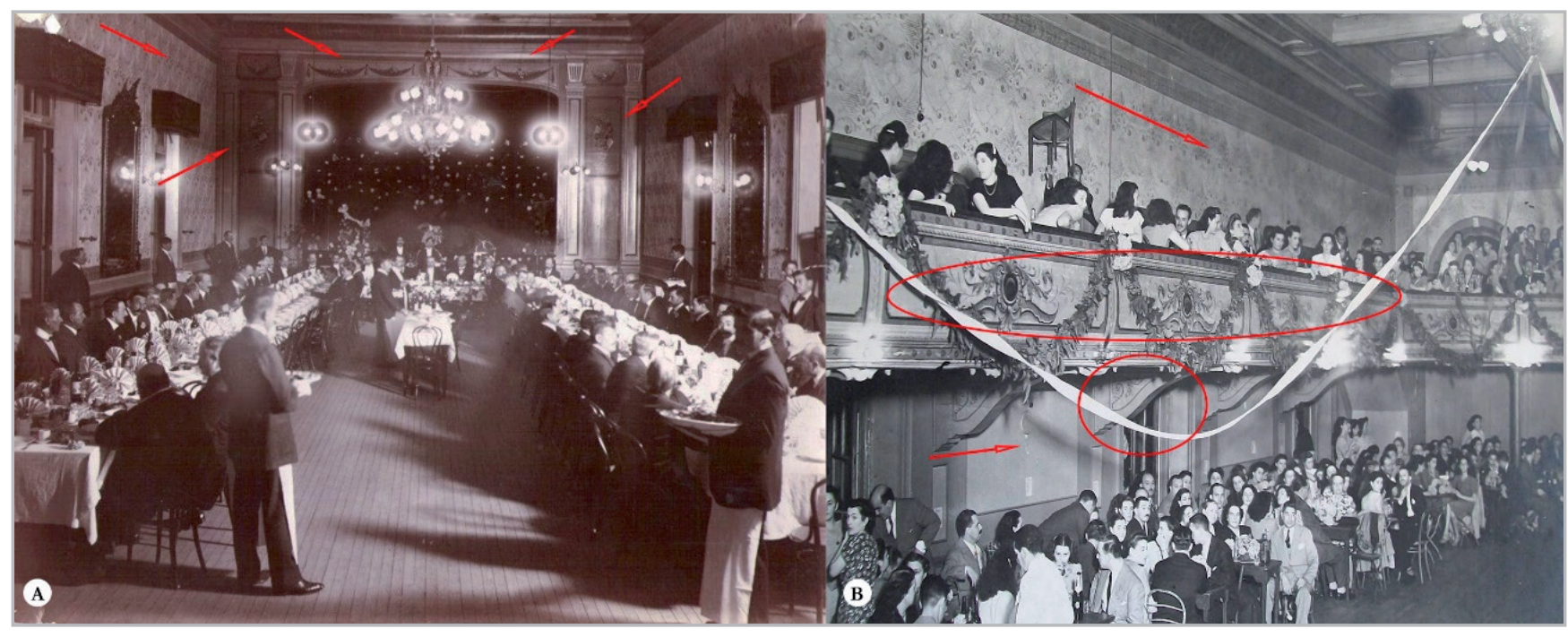

Figura 2.- A: Salón teatral de la Sociedad Italia, Gualeguay. Imagen previa a la reforma de 1910. Se observa la planta única, la decoración mural, y la decoración de los paneles perimetrales a la boca del escenario. B: Frontales y ménsulas decoradas en la línea de palcos, artesonado y decoración mural de la planta alta y pintura lisa en las paredes de la planta baja.

escenario. Tanto en las fotografías de época como en el presente, y sin notorias modificaciones estéticas respecto a aquéllas, se aprecia el majestuoso trabajo del artesonado de la techumbre, también pintado, que remata con un perímetro de molduras cóncavas estampadas con diseños de rosetones [Figura $2 \mathrm{~B}$ ].

Producto de la readaptación de la sala a su nueva identidad, observamos que los cambios estructurales y decorativos introducidos se adaptaron a la estética original, conviviendo en armonía con ella. Por otra parte, la fisonomía de los muros cobró independencia. En la planta baja, ya sea por del desgaste previo del material, por el ocasionado durante la remodelación en el momento de añadir la hilera de palcos, o por la necesidad de sosegar la profusión decorativa, se reemplazó el arabesco de origen por un acabado liso, aparentemente con dos o más tonalidades simultáneamente. En la planta alta, en el sector de los palcos, como se observa en las fotografías antiguas, subsistió el recubrimiento mural de motivos pintados de origen. Es en el frente de los palcos donde se evidencia el acento ornamental mayor, con una decoración de paneles en apariencia pintados, con un gran arabesco central cada uno y enmarcados con guardas de motivos florales. Las ménsulas que ocultan el verdadero soporte estructural del entrepiso también estaban decoradas.

\section{De la descripción al análisis en profundidad. Itinerario de una investigación.}

Dibujos, formas y colores conforman los rasgos que contribuyeron a labrar la identidad de este salón devenido en teatro, la primera y la posterior a sus transformaciones tempranas. Sin embargo, otros vestigios formales latentes, convivieron de manera subyacente y oculta, bajo las numerosascapas de pintura. Repintesquecontribuyeron no sólo a ocultar sino a olvidar por parte de los espectadores y usuarios sucesivos cómo había sido el recinto en sus épocas de esplendor. A partir de aquellos indicios fragmentarios se identificaron los motivos subyacentes, mediante el auxilio de un conjunto de técnicas de adquisición de imágenes y de operaciones de prospección estratigráficas, catas o cateos, complementarias. Con la idea de observar y registrar las imágenes de los posibles decorados subyacentes se empleó la Reflectografía infrarroja. Se utilizó un reflectógrafo infrarrojo portátil, desarrollado por nosotros en base a un sensor tipo Sony CCD (Charge Couple Device) con salida analógica ${ }^{[5]}$. Este equipo trabaja en la Banda denominada NIR (Rango Infrarrojo Cercano de una longitud de onda de 790 a 900 nanómetros) y permite obtener imágenes hasta 100 micras por debajo de la superficie de la pared. Esta técnica, sin embargo no proporcionó en este caso el resultado esperado. Una de las razones se debió al índice de reflectividad de la capa de pintura blanca que recubre las paredes, la cual impidió observar los contrastes determinantes de las formas.

Optamos por la obtención de imágenes fotográficas con luz rasante, utilizando una fuente luminosa halógena tangencial, direccionada con un ángulo entre $5^{\circ}$ y $30^{\circ}$ por encima de la superficie. Con la ayuda de esta técnica pudimos obtener imágenes que evidenciaron los vestigios de los diseños ocultos, su textura y la superficie por donde se extendían esas irregularidades. Los mejores resultados, donde las decoraciones se manifestaron con total continuidad en su recorrido lineal, se obtuvieron en el sector del muro del primer piso, por encima del vano de la escalinata que une ambos niveles. La razón por la que hayan subsistido en aparente buen estado podría deberse a estar en un lugar poco accesible. Allí pudieron ser cubiertas con pintura pero no sufrieron las abrasiones, los desgastes o la desaparición como en otros sectores [Figura 3]. 


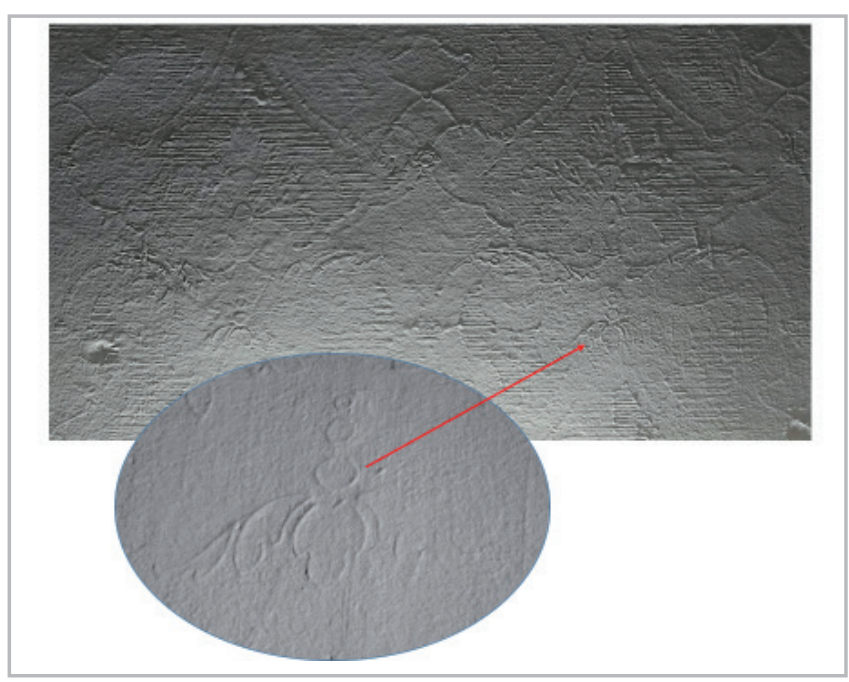

Figura 3.- Detalle en relieve de un fragmento de arabesco que decoraba los muros del Salón teatral de la Sociedad Italia. Fotografía con luz rasante o tangencial.

A fin de estimar la ubicación de las diferentes capas pictóricas que cubren las paredes y tratar de conocer la gama cromática aplicada a lo largo del tiempo, comprobando el aspecto y materialidad de la primera capa de recubrimiento, desarrollamos una serie de diez catas y estratigrafías en las diferentes zonas de ambas plantas.

Para estudiar los films obtenidos en las catas, y organizar los valores de color de las distintas capas que se observaron, utilizamos la técnica espectrofotocolorimétrica, que permite analizar el valor de color de una mezcla pigmentaria mediante un espectrómetro, utilizando el modelo cromático CIELab. A los efectos de encontrar el formato y escala exacta del patrón de diseño más aproximado posible, se efectuaron calcos sobre las zonas en que las imágenes rasantes habían detectado los rastros de decoración y que después de practicar la remoción de los repintes quedaran al descubierto.

Utilizamos Rayos X para examinar la estructura de tres paneles de madera blanda, pertenecientes al lateral superior izquierdo del escenario, a la altura del primer piso. Estas tablas que según las fotografías de época poseían formas pintadas en origen se encontraban desencoladas y sueltas, razón por la que pudimos trasladarlas a nuestra Universidad a realizar el estudio respectivo.

\section{Análisis de Resultados}

Aplicando las metodologías mencionadas en el punto anterior, pudimos comprobar que los vestigios del diseño presente en el muro correspondían a motivos pintados sobre él, tratándose de decoraciones realizadas con la técnica del estarcido con plantilla.
Esta modalidad de estampado fue casi siempre la manera más simple y práctica, para reproducir en soportes variados un mismo motivo de forma repetitiva. Citando a Gombrich:

No podemos saber cómo se hizo el primer patrón, pero podemos estar seguros de que no fue hecho a partir de la nada. Flores, plumas, conchas, piedras son de uso universal, pero antes de ser utilizadas deben ser buscadas, recogidas, seleccionadas $y$, con frecuencia, también preparadas. No existe una rígida línea divisoria entre la elección de tales elementos y su distribución ordenada... hacer, viene antes que comparar... (Gombrich, 1999)

El estarcido ${ }^{[6]}$, sténcil o stampino estuvo muy en auge, en paralelo con las tendencias estéticas del Neogótico, alcanzando un máximo de refinamiento en la segunda mitad del siglo XIX y comienzos del siglo XX. Introducida en Argentina por ingleses, franceses e italianos, esta técnica fue de uso frecuente en paredes y cielorrasos y servía también como complemento decorativo de los materiales de revestimiento importados, como mosaicos, molduras, azulejos, papeles decorados y otros. La reproducción rápida y precisa de los diseños por medio del estarcido con plantillas, permitía que cualquier artesano competente pudiera llevarla a cabo, dejando a los más hábiles concentrarse en el trabajo de trazados o fileteados a mano alzada.

La calidad de la decoración impresa requería de la pericia y exactitud de los moldes, también llamados plantillas, modelos, estampas, pochoirs, patterns o patrones, que podían estar confeccionados en papel, cartón o metales tales como plomo, cobre o cinc, calados o troquelados a fin de generar el diseño correspondiente. Los moldes de papeles resistentes eran los más habituales, de menor costo y fácil fabricación, a diferencia de los metálicos, más duraderos pero difíciles de calar, requiriendo ser trabajados con ácidos, como en las técnicas de huecograbado, tal como los que fueron hallados en la Sociedad Italia [Figura 4]. ${ }^{[7]}$

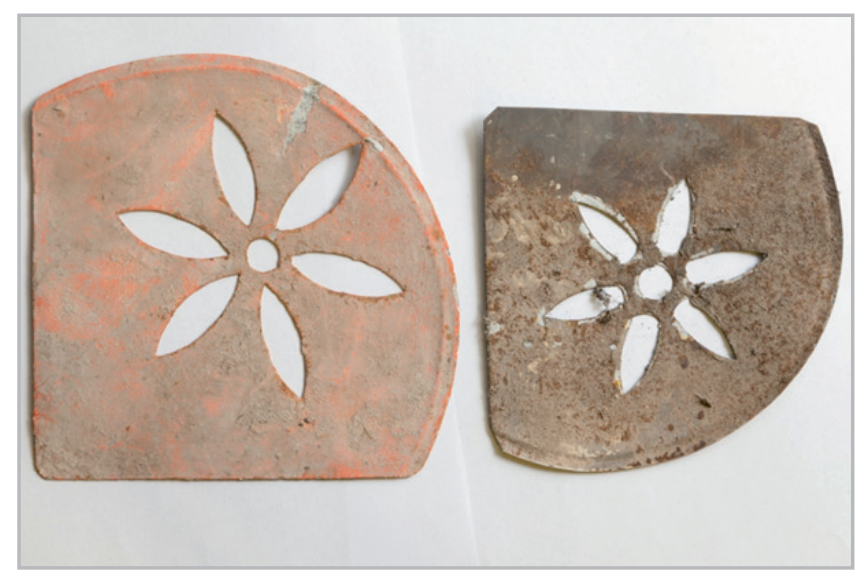

Figura 4.- Imagen de dos patrones de metal para estarcido pertenecientes al acervo del Museo de la Sociedad Italia de Gualeguay. 
Las plantillas de papel necesitaban para su uso y reutilización ser impregnadas en cera o aceites secantes, lo que les confería la maleabilidad e impermeabilidad necesaria para interactuar con cualquier tipo de pintura. Todo motivo que exigiese el empleo de colores diferentes debía ser reproducido por medio de varios moldes, uno para cada color (Cuchy 1908). La pintura a utilizar, tanto fuera de base acuosa con acabado mate, o provista de aglutinantes oleosos con acabados brillantes o satinados, requería que la consistencia tuviese la fluidez necesaria, de consistencia algo más espesa que para la aplicación a pincel. De esta manera se consiguen contornos más nítidos sin chorreaduras (Luft 1948). Una decoración más resistente y duradera -no sería la de nuestro caso- podía también obtenerse aplicando los pigmentos desleídos en agua de cal sobre un mortero de arena y cal, para integrarse íntimamente durante la carbonatación, con el enlucido aún fresco. (Mora 1984).

A partir del indicio primero, procuramos identificar entonces los motivos que desde el interior dejaban rastros de su presencia y finalmente hallamos parte de él, luego de practicar las catas y remociones necesarias. Localizada nuestra inspección en la pared lateral izquierda de la planta alta de la sala, en posición frontal respecto el escenario, dejamos al descubierto casi la totalidad de los vestigios, muy deteriorados, del patrón repetitivo, que sirvió para decorar el muro interior. Este diseño unitario, que se multiplicaría en forma sucesiva en la superficie mural, mide aproximadamente $70 \times 70 \mathrm{~cm}$, y muestra un conjunto de arabescos compuestos por estilizaciones de hojas, plumas, volutas y zarcillos [Figura $5 \mathrm{~A}$.

Los colores observados van desde la tonalidad ocre amarillo al siena natural, correspondiente al fondo o soporte de pared, sobre la cual se asientan diseños de tintes azulados verdosos, tierra verde, tierra sombra natural, blanco y algunas trazas de tierra rojiza que tal vez podrían pertenecer al motivo original o bien al recubrimiento subsiguiente posterior. Según la imagen de la cata y la estratigrafía [Figura 5 B y C], se puede observar desde abajo hacia arriba: la estructura de la argamasa del muro, donde se aprecia la presencia de una carga inerte de considerable granulometría, posiblemente arena y un conglomerante, seguramente cal. Podrían existir dos capas, donde en la superficial, con una carga inerte de partícula más pequeña, también hubiera presencia de yeso. Por encima, los estratos pictóricos, una capa de color tipo ocre amarillo o tierra siena natural, presumiblemente el primer color del muro donde se asentó el diseño estarcido, luego color rojizo oscuro, rosa amarillento, verde claro, blanco y blanco grisáceo, que correspondería al color actual. Corresponde señalar que la caracterización de los componentes del mortero y de la fórmula pigmentaria, formará parte de una próxima investigación.

Las texturas intervinientes son de sumo interés ya que además de haber sido el signo conector entre pasado, presente -subyacente y visible- ostentan una topografía que permaneció en algunos sectores a pesar de los sucesivos repintes y nos indican algunas de sus características particulares. Los perímetros de la mayoría de los diseños muestran una acumulación de material, provocada tal vez por la densidad de la pintura y también por la herramienta y direccionalidad con la que se colocó el material. Esos rastros corresponderían a una densidad medianamente fluida, y a un utensilio como un pincel ancho plano, cepillo plano o espátula, utilizados con un movimiento horizontal.

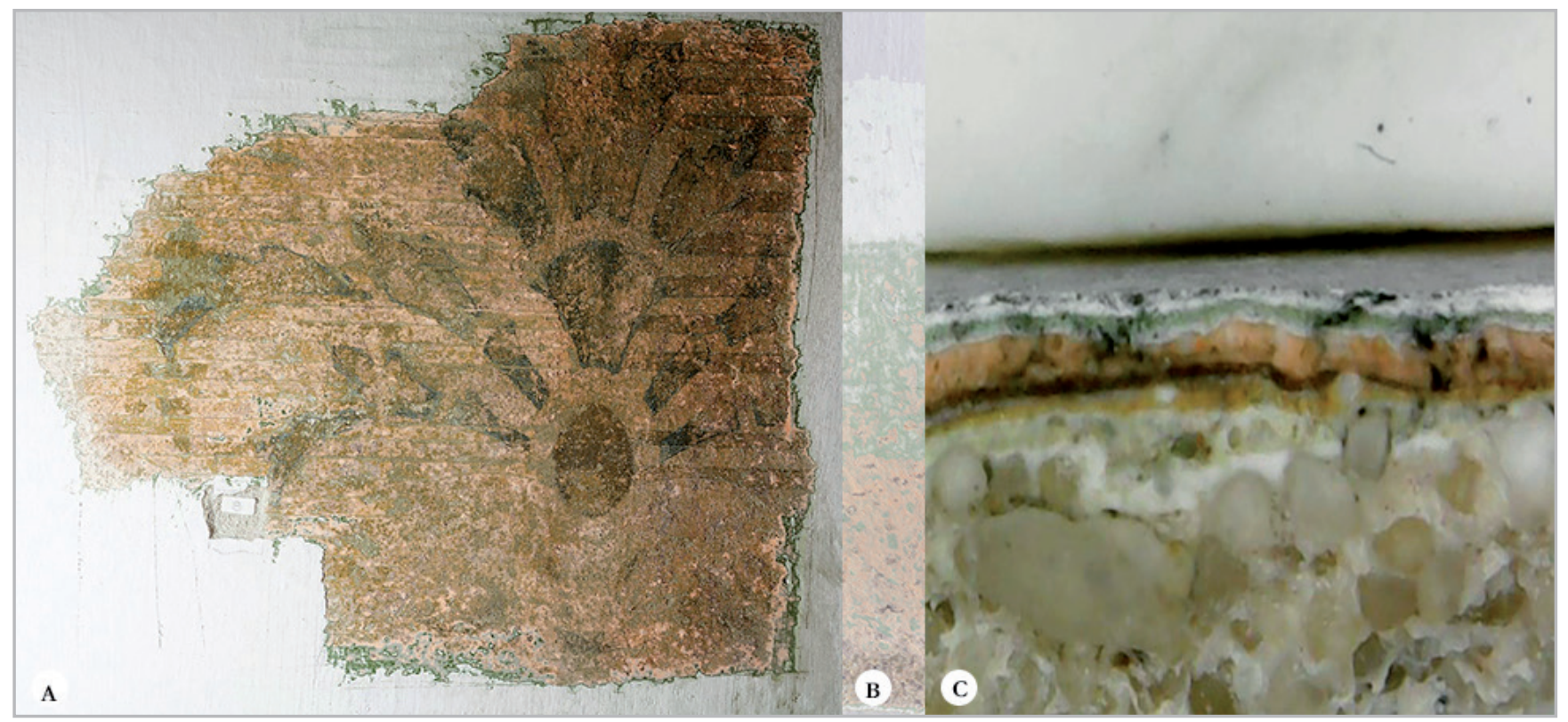

Figura 5.- A: Imagen del diseño estampado con la técnica del estarcido. B: Imagen de la cata próxima al motivo descubierto. Se observan, desde abajo hacia arriba, las tonalidades de las capas de pintura que lo cubrieron sucesivamente. C: Imagen estratigráfica, obtenida del mismo sector. 
También algunas de las texturas muestran una elaborada y sofisticada participación en la consecución del ornato, pudiendo ser las responsables de determinados efectos ópticos lumínicos en la percepción de conjunto. El motivo principal que involucra más formas es una especie de flor de lis, de textura plana, que se encuentra rodeado por una trama escalonada que se inscribe en una superficie romboidea, conformando un estarcido en relieve, aparentemente aplicado en primera instancia. Compuesta de segmentos o cintas transversales de $1 \mathrm{~cm}$ de altura espaciadas a 1 $\mathrm{cm}$ de distancia cada una de ellas, esta trama a modo de rejilla muestra diferencias en el color y en la textura, según corresponda a la mitad izquierda o derecha a ambos lados del arabesco [Figura 6A y B]. En la mitad izquierda, las pequeñas franjas tienen un espesor más elevado que las de la derecha y son de color blanco, a diferencia de las segundas, casi planas y de color tierra verdosa [Figura 6 C]. La sutileza se completa con un esquema opuesto en la pared enfrentada del salón, es decir, que la mitad más clara y reflectante, ya sea por el relieve y/o por el color blanco, se encuentra a la derecha del motivo. Este delicado juego de alternancias provocaría un reflejo y absorción de la luz de una manera muy particular exaltando las formas y la percepción del conjunto decorativo, quizás provocando una sensación ambiental característica. El uso de los estarcidos aporta valor a una superficie monótona y sin relieve y transforma un espacio sencillo en otro de apariencia más rica y sofisticada. Estas razones, sumadas a su sencilla aplicación fueron determinantes para su utilización [Figura $6 \mathrm{D}]$.
Tanto por la morfología como por el juego lumínico pretendido que describimos con anterioridad, podemos establecer una similitud del diseño con los conocidos arabescos adamascados. El damasco fue desde siempre un motivo textil con connotaciones de lujo, usado en tapicería, revestimientos e indumentaria. Originalmente estas telas se tejieron a mano, a menudo en seda, lo que contribuía a reflejar mejor la luz y crear profundidad en los diseños. Desde su aspecto estructural, el damasco es un tejido que utiliza ligamento compuesto, presenta efectos de brillo y mate, debido al reflejo de la luz, al emplear ligamentos escalonados que contraponen un efecto de trama y otro de urdimbre, como el raso o la sarga.

Tratando de asociar el motivo con los de papeles de pared pintados que circulaban por ese tiempo, encontramos un ejemplar fechado entre 1850 y 1880, con una decoración y tonalidad algo similar, que también presenta los trazos horizontales, responsables de insinuar el brillo o reflejo característico que mencionábamos [Figura 7 A].

En el estudio efectuado con anterioridad en otro teatro relevado durante el Proyecto, el teatro Rafael de Aguiar en San Nicolás, Buenos Aires, también se descubrieron vestigios de pinturas estarcidas. Pero esas decoraciones, ubicadas en los tabiques divisorios de los palcos bajos, ocultas en la actualidad por repintes, con sus simples y modestas formas, poco tienen en común con los arabescos observados en el Teatro Italia, de elaborada y cuidada ejecución [Figura 7 B].

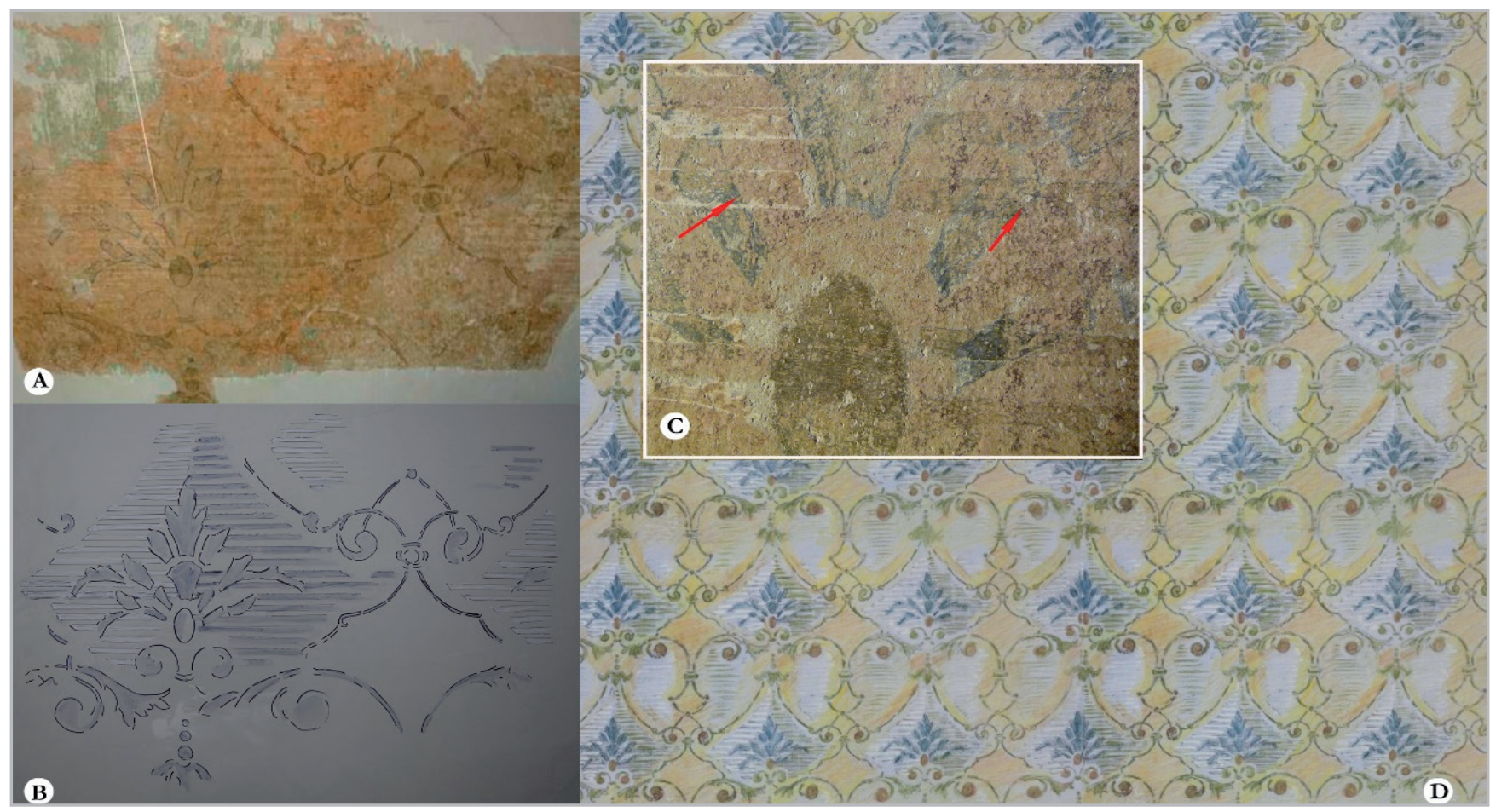

Figura 6.- A: Imagen del estarcido mural original de la sala; algunos trazos fueron reconstruidos a través del calco superpuesto sobre el diseño. B: Dibujo obtenido con calco del patrón repetitivo del diseño estarcido, en base a las medidas reales. C: Detalle del diseño estarcido mural. Se observan las finas franjas o cintas transversales que se disponen en una superficie romboidal y que determinan, según su mayor o menor volumen, las diferentes texturas en alternancia óptica. D: Dibujo que realizamos a partir de los calcos del diseño hallado, coloreado según una de las paletas cromáticas aproximadas a las tonalidades de origen. 


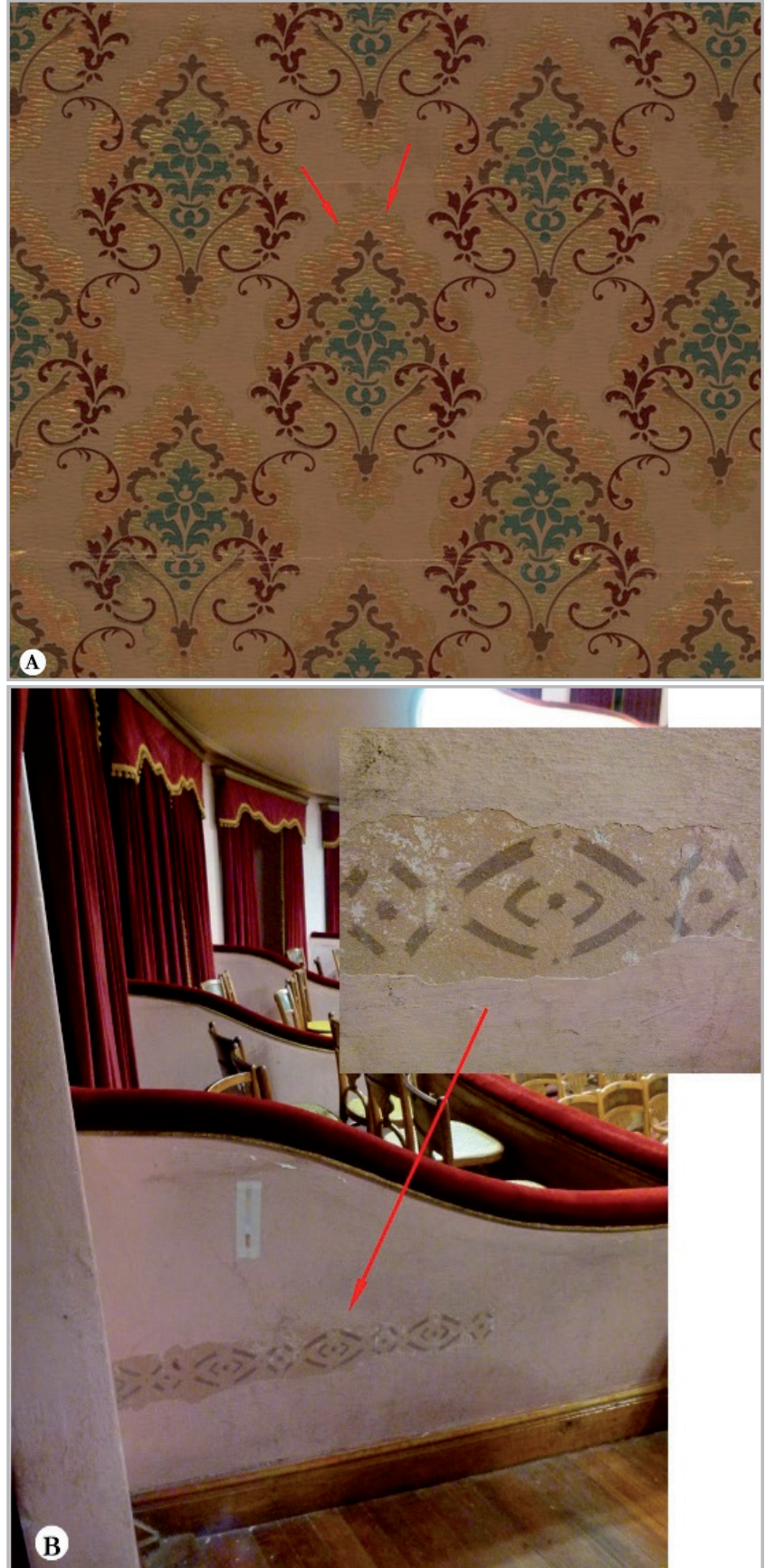

Figura 7.- A: Fragmento de papel pintado, fechado entre 1850 y 1880, perteneciente a la colección del Cooper Hewitt, Smithsonian Design Museum. Donación de Thomas Straham \& Col, Manufactura. B: Detalle del estarcido hallado en los tabiques divisorios de los palcos bajos de la sala del teatro Rafael de Aguiar de San Nicolás, Buenos Aires.

\section{Estudios complementarios}

Asimismo, estudiamos algunas de las tablas constitutivas del tablero de madera ubicado en el muro lateral izquierdo de la boca del escenario [Figura 8 A]. Esta estructura, situada en el centro del muro superior del lateral izquierdo a la embocadura del escenario, correspondería al panel decorado que se observa en la fotografía histórica [figura 8 B] y que en la actualidad, se encontraba pintado de color blanco, como el resto del muro. Está compuesto por una cantidad indeterminada de tablas de madera de pino Thea de $29 \mathrm{~cm}$ de altura, $88 \mathrm{~cm}$ de ancho y $2,5 \mathrm{~cm}$ de espesor, encastradas y encoladas desde su origen. La circunstancia de que cinco tablas de ese panel, tres de las medidas mencionadas y otra compuesta por dos, más un fragmento de la subsiguiente, de $65 \times 88 \times 2,5 \mathrm{~cm}$, se encontrasen desencoladas y desarmadas, fue propicia para poder estudiarlas independientemente del muro, observarlas con luz rasante [Figura $8 \mathrm{C}$ ] y exponerlas a la radiación $X$. Las imágenes radiográficas resultantes se obtuvieron con una técnica de $45 \mathrm{KV}$ y $4 \mathrm{mAs}$ de exposición, y proporcionaron algunos datos de interés. Una franja lateral notablemente radio opaca, al igual que ciertos grafismos ondulantes en la zona central, nos señalaba la presencia de algún elemento químico de alta densidad, como tal vez un pigmento a base de Plomo, y nos alentaba a suponer la existencia aún, de las pinturas decorativas subyacentes [Figura $8 \mathrm{D}$ ]. Complementamos el estudio con la remoción de las capas superpuestas de los repintes, una superior de pintura blanca de naturaleza acuosa y otra subyacente de color verde claro de naturaleza oleosa, dejando así al descubierto un motivo central de colores variados y unas guardas laterales con base de tonalidad rojiza, posiblemente Minio (tetróxido de Plomo) [Figura $8 \mathrm{E}$ ].

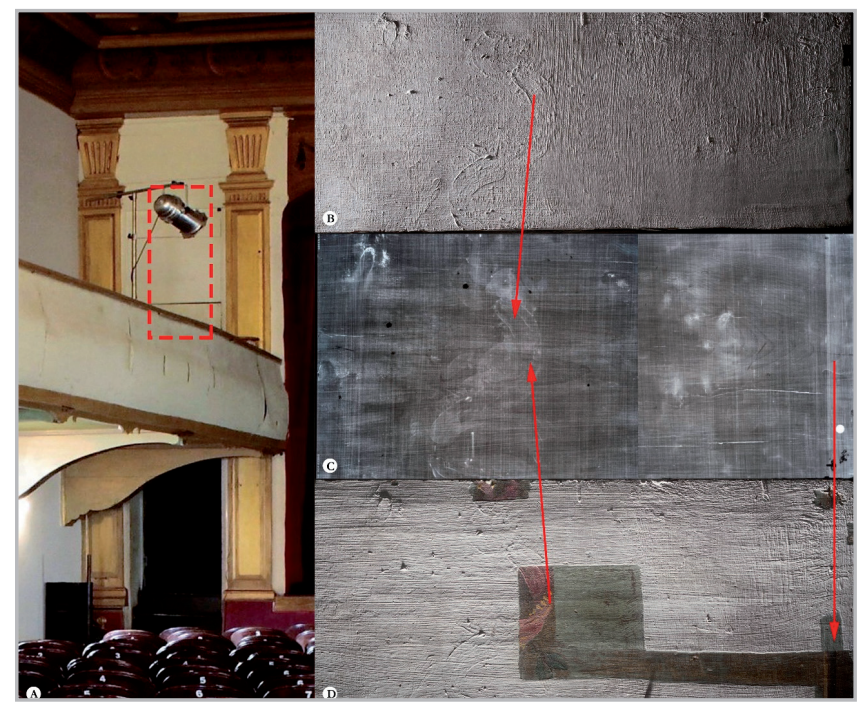

Figura 8.- A: Vista actual del muro lateral izquierdo del escenario, se observan los paneles centrales pintados de color blanco, con los cortes o grietas en la madera, que facilitaron la remoción momentánea de las distintas tablas encoladas que lo formaban. B: Fotografía con luz rasante de una de las tablas que pudieron trasladarse para ser estudiadas y restauradas. C: Imágenes radiográficas del panel estudiado. D: Imagen de una de las tablas de madera en proceso de restauración. Se observa la remoción de las capas que recubren el diseño pintado original.

Cuando se finalicen los procedimientos de restauración en los cinco tableros de madera, podremos acceder al diseño pintado y sus materiales constitutivos, casi 

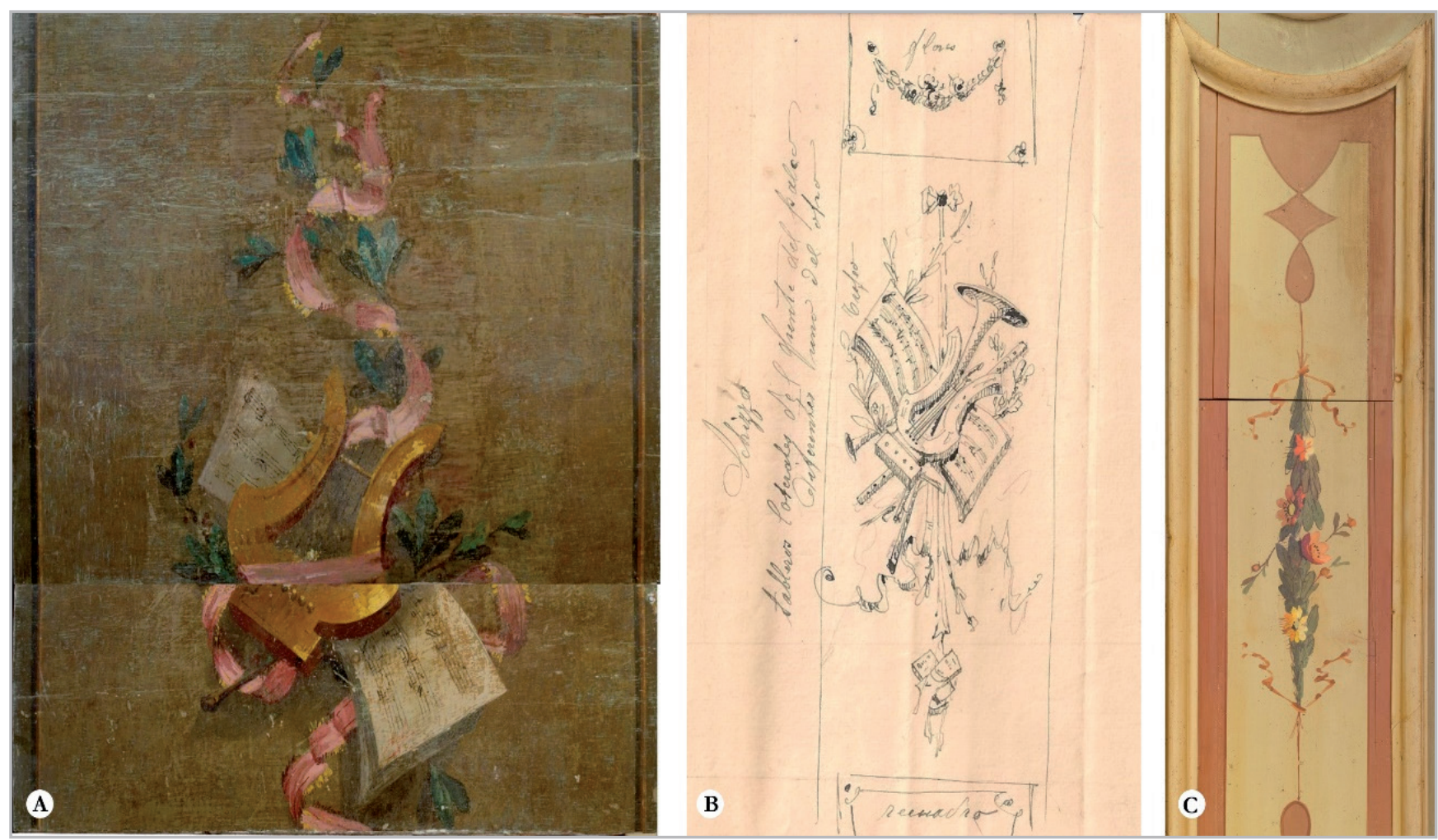

Figura 9.- A: Imagen de un fragmento del tablero decorado, del sector izquierdo de la boca del escenario, durante el proceso de restauración. Se observa parte del panel decorado tras la remoción de las capas de pintura que lo cubrían. B: Imagen de dibujo o boceto realizado aparentemente con pluma y tinta. En el mismo se lee: Schizzo tableros laterales del frente del palco diferentes uno del otro -- flores /Trofeo recuadro C: Imagen de fragmento de panel perimetral perteneciente a la decoración del artesonado del techo. Se observa una gran similitud de las formas orgánicas respecto al boceto de tinta anterior.

en su totalidad [Figura 9 A]. Los mismos aparentan estar ejecutados con pintura de aglutinante oleoso y recubierta con un acabado de apariencia semejante a la goma laca. La paleta oscila entre tonalidades de blanco, amarillo, ocre amarillo, rojo carmín oscuro, rojo con blanco, verdes, tierras y mezclas. Se buscará cotejarlo también con uno de los bocetos perteneciente al museo de la Sociedad Italia [Figura 9 B] ya que podría haber sido el modelo que inspiró su realización, así como con otras de las decoraciones sobre madera del mismo teatro [Figura $9 \mathrm{C}$ ].

\section{Reconstrucción virtual de la sala}

La metodología experimental empleada en este trabajo, se compone de dos etapas interrelacionadas. La primera, la adquisición de imágenes a partir de fotografías realizadas con una cámara Canon $5 d$ Mark II con una lente Canon EF 24-105 L IS USM. Las imágenes se adquirieron con la propia luz de la sala y se configuró la cámara para una larga exposición, lo que permitió cerrar el diafragma para obtener una buena profundidad de campo. La postproducción se efectuó mediante el programa Photoshop CC, instalado en una plataforma Mac Station con microprocesador I5. Los colores de las paredes fueron asignados a partir de la información obtenida a partir de las catas, mediante espectrocolorimetría, analizando las sucesivas capas de pigmentos que se hallaron en las mismas. La segunda etapa, implicó el procesamiento manual de las imágenes, efectuado con la participación interactiva de los investigadores. Se partió de la fusión de 2 imágenes, una expuesta correctamente para la zona de iluminación directa y otra para las sombras. Una vez obtenida una foto básica se eliminaron vestigios de modernidad (matafuegos, sistemas de sonido, etc.) y se prefirió conservar la línea de butacas a la de las sillas individuales. Por último, se aplicaron los diseños decorados, tanto sobre las paredes laterales como en el frente de los palcos, superponiendo una capa con opacidad del $80 \%$, preservando de esa forma la luminosidad natural del lugar. Para finalizar se optimizó este ajuste corrigiendo previamente la perspectiva.

Cabe destacar que ambos motivos, los correspondientes al frente de palcos y muros, están basados en información real obtenida en el lugar. Los primeros se obtuvieron en base a dibujos e interpretaciones de las fotos antiguas y de los vestigios originales, hallados con anterioridad, por el personal del Teatro Italia. Y los diseños murales corresponden a la fotografía del dibujo de la trama en escala, que elaboramos a partir de los calcos directos sobre los motivos descubiertos, guiados por las fotos históricas y coloreándolos con una gama aproximada a la de origen [Figura 10]. 

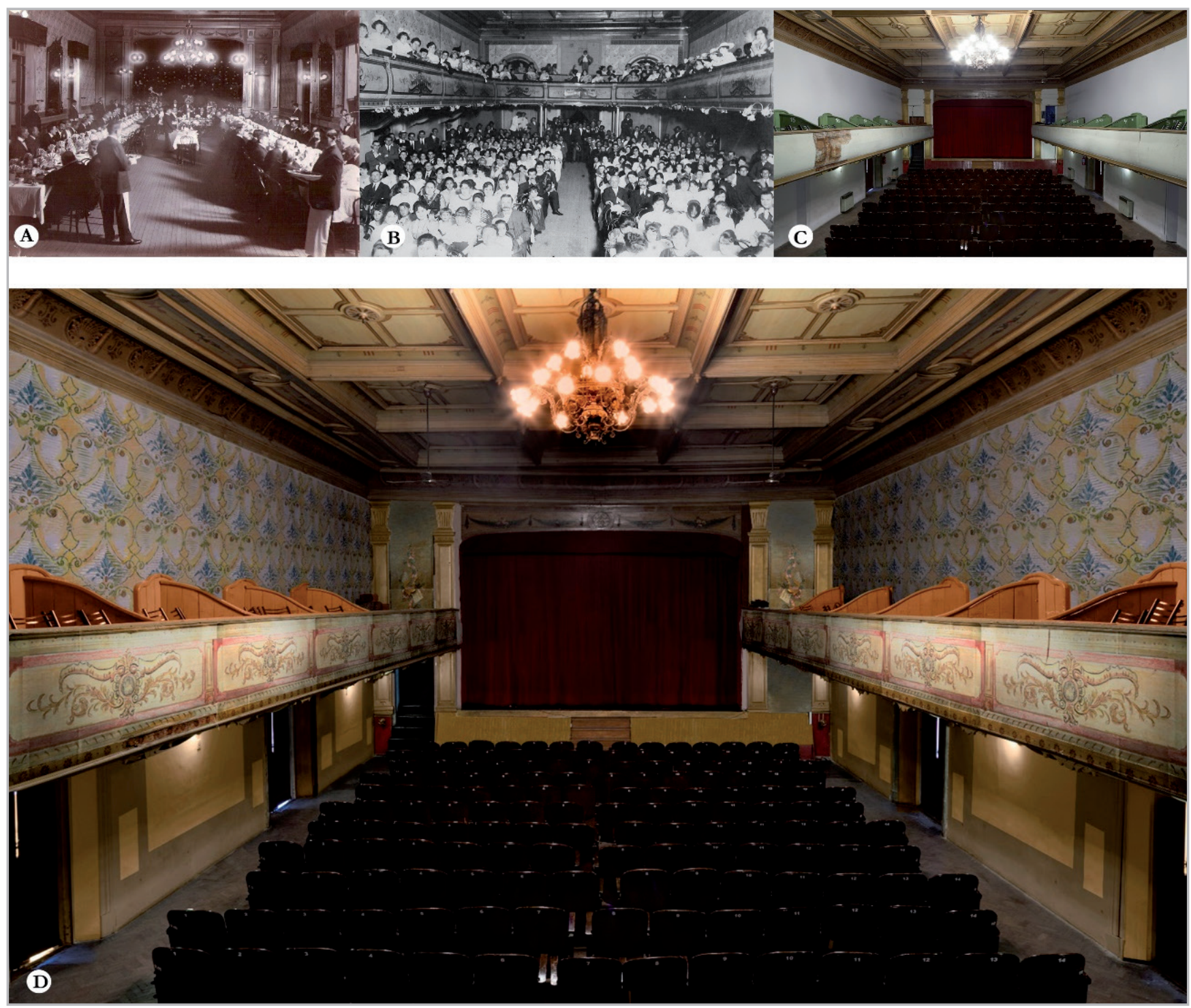

Figura 10.- A: Salón teatro de la Sociedad Italia antes de la reforma de 1910. B: Sala del Teatro Italia, después de la reforma de 1910 c. 1930. C: Sala del Teatro Italia en la actualidad, 2018. D: Reconstrucción virtual del interior de la sala, teniendo en cuenta aspectos formales y cromáticos aproximados, a partir de los resultados obtenidos y en relación con la documentación histórica.

\section{Conclusiones}

A partir de las observaciones, estudios y análisis realizados, pudimos:

1. Reconstruir la decoración mural que ostentaba la mayor parte de la pared de la planta única de la sala del teatro Italia entre 1903 y 1910 . Se trataba de una pintura realizada con la técnica del estarcido con plantilla, con algunas de sus texturas en relieve.

2. Recomponer dicho diseño estarcido mural, obteniendo la medida y proporción exacta, a través de calcos directos, sobre los motivos descubiertos, guiados por las fotos históricas de referencia.

3. Determinar el impacto de las reformas de 1910 que convierten la sala única en 2 plantas. En la planta superior subsiste la decoración mural mientras que en la inferior, desaparece. Las paredes se pintan en dos o más tonalidades.
4. Descubrir que los motivos pintados en los paneles a ambos lados del escenario fueron cubiertos por capas de pintura, siendo el del sector izquierdo (vista frontal) el único que subsiste.

El conjunto de estas investigaciones y sus resultados, más otras que continúan desarrollándose como parte de este proyecto, podrán integrarse en las imágenes producidas para una reconstrucción digital virtual de los distintos e hipotéticos momentos históricos-estéticos de la sala teatral. En la [Figura 10] se propone uno de esos ejercicios que reúne el estado actual de las investigaciones.

El recurso de las herramientas digitales, aplicadas al campo de la restauración y conservación de Bienes Culturales, ofrece grandes ventajas y se afirma como el auxiliar imprescindible para visualizar posibles soluciones o alternativas al momento de pensar y decidir un trabajo de restauración. De esta manera podemos interpretar de 
manera virtual y anticipada, el posible aspecto del bien ya restaurado o intervenido sin límite de posibilidades u opciones. De posible acceso a todos los especialistas, contribuye a plasmar un consenso antes de emprender la restauración material de la obra. También es el accesorio más elocuente al momento de obtener los recursos materiales necesarios para emprender los trabajos, generando la seguridad de los dadores de las subvenciones, al crear una prospectiva posible y con el compromiso de un trabajo bien estudiado y con favorables resultados.

Resulta interesante citar, que Riegl, ya en 1903, avizoraba la posibilidad y necesidad de imaginar y crear estas soluciones, ...teniendo en cuenta el creciente desarrollo de los medios de reproducción artístico-técnicos, se puede confiar en que en un futuro previsible (especialmente tras el descubrimiento de una fotografía en color absolutamente convincente y de la combinación de ésta con copias tipo facsímil) se podrán encontrar sustituciones lo más perfectas posible de los originales documentales. Con ello se podrán satisfacer, al menos de un modo aproximado los postulados de la investigación histórica, científica, que constituye la única fuente de posibles conflictos con el valor de antigüedad, sin que, debido a la intervención humana, el original pierda valor para el culto a la antigüedad.

\section{Notas}

[1] El presente trabajo forma parte del proyecto Proyecto PICT 3831-2015 dirigido por Fernando Devoto de la Agencia Nacional de Promoción Científico-Tecnológica (ANPCYT) de la Argentina. Agradecemos a Alicia Bernasconi y Fernando Devoto por las observaciones y comentarios al artículo. También queremos expresar nuestro agradecimiento a Stella Zucco por su trabajo en el Laboratorio de Rayos X. A Sergio Redondo por todo su apoyo en técnicas fotográficas .y el aporte efectuado en el procesamiento de imágenes de reconstrucción virtual. A Luciana Feld y Alejandra Rubinich, por su trabajo en la confección de estratigrafías y, en general, a todos los integrantes del Instituto de Investigaciones sobre el Patrimonio Cultural, IIPC - TAREA. Asimismo, gracias a todos aquellos que en la ciudad de Gualeguay nos brindaron su colaboración. En especial a José Della Giustina, Américo Detomasi, Facundo Cichero, Ricardo Mugnai, Graciela Beheran, Agustina Carbone y demás integrantes de la Comisión Directiva de la Sociedad Italia. A Gastón Marcó, Diario El Debate y a Julián Lazo.

[2] DEVOTO, F. "Historia de los italianos en la Argentina”, Capítulo 3 - Intermedio. Las instituciones de los italianos en la Argentina, Buenos Aires, 2006.

Una diferencia visible en las asociaciones mutuales de la Argentina comparadas con las de otras partes es la riqueza de las mismas. Un ejemplo adicional de esa mayor fortaleza de las asociaciones argentinas es que la casi totalidad de las sociedades eran dueñas del lugar en el que funcionaban. Los ingresos regulares de las mismas ayudados a veces por gestos filantrópicos de connacionales exitosos les permitían comprar el terreno y construir poco tiempo después de haber sido fundadas.

[3] Sesión del Consejo Directivo del 10 de marzo de 1910. Libro de actas $n^{\circ} 10$, p.168. En Bernasconi, A. Las ambigüedades de un teatro de ópera. El caso de Gualeguay, Academia Nacional de la Historia.

[4] Fotografías antiguas pertenecientes al Museo J.B. Ambrosetti de Gualeguay y al Museo de la Sociedad Italia, Teatro Italia de Gualeguay.

[5] SAULINO, D. y otros. (2008). "Imágenes de lo Invisible. Adquisición y Análisis de Imágenes Infrarrojas", en Eadem Utraque Europa [La misma y la otra Europa] 7: 161-185. Miño y Dávila editores.

[6] Nota del autor: al emplear en este trabajo el término estarcido, o estarcido con plantillas, nos referimos al procedimiento de estampación de un diseño con el auxilio de plantillas, troqueles o trepas. Y lo distinguimos del homónimo, que se aplica al procedimiento usado para traspasar un dibujo preparatorio realizado en un papel o cartón a otro soporte definitivo. Éste último, el estarcido espolvoreado, es el que permite replicar dicho dibujo, a través de las perforaciones de su perímetro y por donde se cuela el pigmento seco que lo determinará. Sobre estarcido espolvoreado ampliar en: (Bruquetas Galán, 2002), (Cennino, 2002, pp 176), (Rallo Gruss, 1999, pp. 103, 319), (Mora, Mora \& Philippot, 1984).

[7] Moldes metálicos para estarcido pertenecientes al acervo del Museo de la Sociedad Italia de Gualeguay, fueron hallados durante refacciones, ocultos bajo un esquinero de madera de uno de los techos del edificio de dicha Sociedad. Se constató su forma con las diferentes figuras de las decoraciones existentes en las guardas murales, en los motivos pintados del artesonado del techo, en las decoraciones murales estarcidas y otras, pero no se encontró correspondencia con ninguno de esos diseños. Gentileza y relato de Facundo Cíchero.

\section{Referencias}

BERNASCONI, A (2017). Las ambigüedades de un teatro de ópera. El caso de Gualeguay, Academia Nacional de la Historia.

BRUQUETAS GALÁN, R. (2002). Técnicas y materiales de la pintura española en los Siglos de Oro. Ed. Fundación de Apoyo a la Historia del Arte Hispánico.

CENNINO, C. (2002). El libro del arte, Akal, Madrid.

CUCHY, J. (1908). Manual del pintor decorador. Barcelona- Buenos Aires: Sucesores de M.Soler

FERRETERÍA F. (1939). Catálogo llustrado de la Sección Herramientas. Buenos Aires: Estrabou y Cía.

GOMBRICH, E.H. (1999). (1979). El Sentido del Orden. Estudio sobre la psicología de las artes decorativas. Madrid: Debate. 
HALL, K. (1994). Decorative Stencilling. London: Merehurst.

HOWELL, K. (2014). Victorian and Edwardian Stencilled Decoration. https://www.buildingconservation.com/articles/stencilleddecoration/stencilled-decoration.htm [consulta: 01/12/2018].

LEHNERT, G. (1933). Las Artes Industriales. Barcelona: Editorial Labor.

LOPEZ CODA, P. (1998). Artes Aplicadas a la Arquitectura. Los Estarcidos en Buenos Aires. http://www.iaa.fadu.uba.ar/ publicaciones/critica/0089 [consulta: 01/12/2018].

LUFT, P.F. (1948). La pintura y su aplicación. Buenos Aires: Ediciones Librería del Colegio.

MARCONI, E. (2012). American Decorative Stenciling: 1840 to 1940. Columbia University. https://academiccommons.columbia.edu/ doi/10.7916/D8DN4C8Z/download [consulta: 01/12/2018].

MAULE, M. (1991). Decorative Stencils for Interior Design. London: Studio Vista.

MAYER, F. (1849). A Handbook Of Ornament. New York: The Architectural Book Publishing Company. https://archive.org/ details/handbookoforname00meye/page/n6.

MORA P. MORA L., PHILIPPOT, P. (1999). La conservazione delle pitture murali, Bologna, Compositori.

MORA, P., MORA L. (1984). “Le Superfici Architettoniche, Materiale e Colore. Note ed esperienze per un approccio al problema del restauro", Bolletino D'Arte. Ministero per i Beni e le Attivita Culturali, 6:17-24.

MORENO RICHTER, G. (1949). Pintura y Decoración de Casas. Buenos Aires: Klug, Marchino y Cía. Editorial Pan América.

PERIÓDICO EL DEBATE. Gualeguay, Entre Ríos.

RALLO GRUSS, C. (1999). Aportaciones a la técnica y estilística de la Pintura Mural en Castilla a final de la Edad Media. Tradición e Influencia Islámica. Vol I. Tesis Doctoral UCM.

RIEGL, A. (2008). El culto moderno a los monumentos. Madrid: La Balsa de la Medusa.

SAULINO, D. et al. (2008). "Imágenes de lo Invisible. Adquisición y Análisis de Imágenes Infrarrojas", Eadem Utraque Europa [La misma y la otra Europa] Vol 7. Miño y Dávila editores.

VALLEJO, F. J. (1953). Pinturas y Barnices. Buenos Aires: Klug, Marchino \& Cía. Editorial Pan América.

VICO, H. (1976). Historia de Gualeguay. Desde sus orígenes hasta 1910. Santa Fe, Argentina: Librería y Editorial Colmegna S.A.

VICO, H. (1976). Historia de Gualeguay. 1910- 1940. Santa Fe, Argentina: Librería y Editorial Colmegna S.A.

\section{Autor/es}

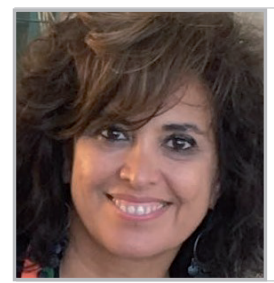

María Alejandra Gómez Paredes

alegomezparedes@gmail.com

Centro TAREA, Instituto de Investigaciones sobre el Patrimonio Cultural. UNSAM, Universidad Nacional de San Martin (Argentina).

Profesora de Artes Visuales y de Conservación Restauración desde 2004 en TAREA - IIPC, de la Universidad Nacional de San Martín, Buenos Aires, Argentina. Profesora especialista en Pintura y Dibujo, egresada de la Escuela Nacional Prilidiano Pueyrredón / UNA Universidad Nacional de las Artes. Formada como Restauradora y Conservadora en el Taller del Prof. Néstor Barrio. Trabajó en el Museo Nacional del Grabado y en el Museo Nacional de Bellas Artes. Desarrolla complementariamente, trabajos de investigación asociados al Laboratorio de Análisis de Imágenes Multiespectrales (UV, IR, RX), en el IIPC de la UNSAM. Becada en 1999 por el Fondo Nacional de las Artes, Museo Guggenheim de Bilbao y Fundación Proa, participó de Diseño, Gestión y Planificación de eventos en arte contemporáneo. Como artista visual, asiste activamente a clínicas y seminarios junto a artistas visuales como Eduardo Stupía y Manuel Ameztoy, entre otros.

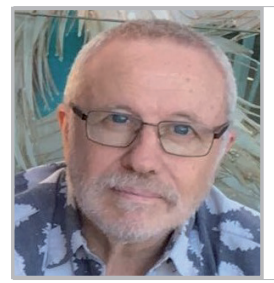

\section{Daniel Alberto Saulino}

dsaulino@gmail.com

Escuela de Ciencia y Tecnología y Centro TAREA - IIPC, UNSAM, Universidad Nacional de San Martín (Argentina).

Profesor en Electrónica y Licenciado en Tecnología egresado de la Universidad Tecnológica Nacional. Trabajó para la Comisión Nacional de Energía Atómica (CNEA), en la División Microscopia Electrónica y Difracción de Rayos X, desde 1977 hasta 1995. Desde 1995 hasta la fecha se desempeña en la Universidad Nacional de Gral. San Martín, en la Escuela de Ciencia y Tecnología y en TAREA - Instituto de Investigaciones del Patrimonio Cultural, como Profesor - Investigador en el Laboratorio de adquisición y análisis de imágenes multipespectrales, aplicadas al estudio de obras del patrimonio cultural. Participa como investigador en proyectos de I+D; y acredita varias publicaciones de la especialidad.
Artículo enviado el 10/01/2020 Artículo aceptado el 11/07/2020

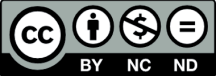

https://doi.org/10.37558/gec.v18i1.727 